Saudi Journal of Medical and Pharmaceutical Sciences

Abbreviated Key Title: Saudi J Med Pharm Sci

ISSN 2413-4929 (Print) |ISSN 2413-4910 (Online)

Scholars Middle East Publishers, Dubai, United Arab Emirates

Journal homepage: https://saudijournals.com

Original Research Article

\title{
Lupus Nephritis in the Military Hospital of Morocco: Clinicopathological Features and Management
}

\author{
Dr. Mounia Azizi ${ }^{*}$, Dr. Ahmed Alayoud ${ }^{2}$, Dr. Yassir Zajjari ${ }^{1}$, Dr. Abdelali Bahadi ${ }^{1}$, Dr. Driss Kabbaj ${ }^{1}$ \\ ${ }^{1}$ Nephrologist, Department of Nephrology-Dialysis, Military Hospital Mohammed V, Hay Ryad BP 10100 Rabat, Morocco \\ ${ }^{2}$ Professor of Nephrology, Department of Nephrology-Dialysis, Military Hospital Agadir, Morocco
}

\begin{tabular}{ll}
\hline DOI: $10.36348 /$ sjmps.2021.v07i03.001 & | Received: 27.02 .2021 | Accepted: 17.03 .2021 | Published: 21.03 .2021 \\
*Corresponding author: Dr. Mounia Azizi &
\end{tabular}

*Corresponding author: Dr. Mounia Azizi

\section{Abstract}

There is a large variety in prevalence, clinicopathological features and management of lupus nephritis (LN) between patients worldwide. Data from North Africa are extremely lack, particularly from Morocco. The aim of this retrospective study was to describe clinicopathological features as well as treatment and outcome of patients with biopsy proven LN in a region of Morocco. A total of 54 patients were included between January 2008 and December 2018. LN was classified according to the International society of Nephrology/Renal Pathology Society. The mean age of the patients was $28+/-11$, 76; female gender was preponderant $(91 \%)$. At first presentation, hypertension, hematuria, proteinuria and renal failure were observed in $74 \%, 74 \%, 83 \%$ and $48 \%$ respectively. Renal biopsy performed in all patients revealed proliferative classes in $76 \%$. Conservatively treatment was adopted in all patients. $61 \%$ of patients with joint and mucocutaneous manifestations received antimalarial drug. All patients with proliferative classes received immunosuppressive regimens based on either intravenous cyclophosphamide (43\%) or oral mycophenolate mofetil (33\%). At 6 months, remission was achieved in $85 \%$, end stage renal disease in $4 \%$ and death in $6 \%$. Adverse events due to immunosuppressive drugs were mostly dominated by infections (41\%), leukopenia (20\%) gastrointestinal symptoms $(31 \%)$ and gonadal toxicity (24\%). From our view, the outcome of Moroccan patients with LN may be better than commonly thought. However, disparities seen from several studies in our country can be assigned to the precariousness of health system and the low socioeconomic level of population.

Keywords: clinicopathological features, lupus nephritis (LN), Nephrology/Renal Pathology Society.

Copyright () 2021 The Author(s): This is an open-access article distributed under the terms of the Creative Commons Attribution 4.0 International License (CC BY-NC 4.0) which permits unrestricted use, distribution, and reproduction in any medium for non-commercial use provided the original author and source are credited.

\section{INTRODUCTION}

Renal disease in systemic lupus erythematous (SLE) is one of the most frequent manifestation of this disease and occurs in more than half of SLE patients. It is also one of the most severe complications of SLE; therefore, it remains the leading cause of death in these patients $[1,2]$.

The clinical features of lupus nephritis (LN) are heterogeneous, ranging from mild asymptomatic proteinuria to rapidly progressive glomerulonephritis leading to end stage renal disease, thus, renal biopsy remains the gold standard in management of LN [3].

Renal injury in LN seems to be driven by the inflammatory response to immune complex which can deposit anywhere in kidney, and other mechanisms, including endothelial injury, podocytopathy and tubulointersticiel injury [4].
Consequently, treatment and outcome range from excellent prognosis with only mesangial deposit, to end stage renal disease (ESRD) inspite of aggressive immunosuppressive drugs in patients with severe proliferative disease [5].

A few studies describing LN were reported in Arab world and especially in North Africa [6-8]. In Morocco, one descriptive study was conducted in Ibn Sina Hospital of Rabat between 2001 and 2010 but treating patients according to former protocols. Thus, so as to have an update of $\mathrm{LN}$ in Morocco, we reviewed retrospectively 54 cases of $\mathrm{LN}$ in our department between 2008 and 2018. The aim of our study was to describe the clinicopathological features as well as treatment and outcome.

\section{MATERIEL AND METHODS}

This retrospective study included all patients with biopsy-proven LN between January 2008 and 
December 2018 at the Military Hospital Mohammed V of Rabat, Morocco.

Renal biopsies were processed for light and immunofluorescence microscopy in all specimens. Sections were stained with hematoxylin and eosine, Masson's trichrome, periodic acid Schiff and silver Jone's stain.

Histological findings were evaluated using the International Society of Nephrology/Renal Pathology Society 2003 classification of LN [9].

All patients met the American Rheumatism Association criteria for SLE classification (at least 4 criteria) [10].

The diagnosis of LN was based on the presence of a persistant proteinuria greater than $0,5 \mathrm{~g}$ per day and /or active urinary sediment/cellular casts and/or hematuria and/or acute increase in serum creatinine.

We recorded the following parameters: demographic data (age, gender), clinical symptoms (blood pressure, mucocutaneous signs, joint manifestations, vascular, pleuropulmonary, neurological and cardiac signs), biological parameters (serum creatinine, estimated glomerular filtration rate (eGFR), urinalysis including proteinuria from a 24-hour collection and hematuria ,blood count, antibodies against ds DNA antinuclear antibodies and complement component C3-C4), therapy and outcome. The eGFR was calculated using the modified diet in renal disease study equation.

The therapeutic protocol that we used in our patients was as follows. All patients were treated by conservatively care. The presence of mucocutaneous and articular manifestations conditioned the intake or not of antimalarial drug. All patients with proliferative classes received a 3 day pulse of methylprednisolone followed by oral corticosteroids and gradually tapered. Immunosuppressive treatment consisted of six monthly pulses of intravenous (IV) cyclophosphamide (CYC) with high doses or biweekly during 3 months with low doses or mycophenolate mofetil (MMF) at a dose of 2 to $3 \mathrm{~g}$ per day splited as induction therapy. Subsequent maintenance treatment was either with MMF (1 to $2 \mathrm{~g}$ /day) or azathioprine (2-3 mg/Kg body weight).

All women patients were sexually active and were informed of the risks of lupus during pregnancy and agreed to postpone the pregnancy until the disease subsided.

One therapeutic evaluation was performed at 24 weeks of diagnosis. Treatment response was assessed as complete remission (CR), partial remission
(PR), or no response. Outcome measures were defined as per kidney Disease improving Global outcome KDIGO [11]:

CR: Return of SCr to the previous baseline, plus a decline in the urinary protein to creatinine ratio (uPCR) to $<500 \mathrm{mg} / \mathrm{g}$.

PR: Stabilization (+/- 25\%), or improvement of $\mathrm{SCr}$, but not to normal, plus a >decrease in uPCR. If there was nephrotic range proteinuria ( $\mathrm{uPCR}>3000 \mathrm{mg} / \mathrm{g}$ ), improvement required a $>50 \%$ reduction in $\mathrm{uPCR}$, and an $\mathrm{uPCR}<3000 \mathrm{mg} / \mathrm{g}$.

Deterioration was defined as a sustained $25 \%$ increase in SCr. The adverse events during treatment were recorded.

Data with continuous variables were presented as mean \pm standard deviation. Categorical variables were presented as effective and percentage. Statistical analysis was performed with Statistical Package for the Social Sciences (SPSS) version 10.0 (SPSS Inc., Chicago, IL, USA). The study was approved by the Ethical Committee of the institution.

\section{RESULTS}

\section{Demographic, clinical and laboratory features}

Over the 11-year period, 54 cases of LN were included in this study, constituting $12 \%$ of all native renal biopsies performed on this period $(n=457)$. Among the 54 patients with LN, 49 (91\%) were female, $5(9 \%)$ were male with an average age of $28+/-11,76$ (14-55) years at the time of renal biopsy.

At admission, $63 \%$ of the patients presented with $\mathrm{LN}$ at the diagnosis of SLE. In patients with noninaugural renal disease, time between diagnosis of SLE and $\mathrm{LN}$ was $10,2+/-4,2$ months.

Initial presentation of SLE was predominated by joint manifestations (78\%) and mucocutaneous symptoms (67\%). Furthermore, most renal manifestations were edema of the lower limbs (83\%) and hypertension $(74 \%)$.

Hematuria was seen in $40(74 \%)$ patients. Proteinuria was found in $45(83 \%)$ patients with a nephrotic range in $15(28 \%)$ patients and renal failure in $26(48 \%)$ patients. There was a need of renal replacement therapy (RRT) in $2(4 \%)$ patients. Anti -ds DNA antibody was present in $91 \%$ of patients. Low component of complement $\mathrm{C} 3$ and $\mathrm{C} 4$ were seen respectively in $80 \%$ and $76 \%$ of patients.

Table-1 summarized demographic clinical and laboratory characteristics of the patients. 
Table-1: Demographic, clinical and laboratory characteritics of the 54 patients

\begin{tabular}{|l|l|}
\hline Characteristics & Number (\%) \\
\hline Number & 54 \\
\hline Age (years) & $28+/-12$ \\
\hline Male & $5(9)$ \\
\hline Female & $49(91)$ \\
\hline Hypertension & $40(74)$ \\
\hline Renal failure & $26(48)$ \\
\hline eGFR at the time of diagnosis (ml/min) & \\
$>90$ & $28(52)$ \\
$60-90$ & $4(7)$ \\
$30-60$ & $9(17)$ \\
$15-30$ & $10(19)$ \\
$<15$ & $3(6)$ \\
Proteinuria>500mg/day & $45(83)$ \\
Nephrotic syndrome & $15(28)$ \\
Hematuria & $40(74)$ \\
Mucocutaneous signs & $36(67 \%)$ \\
\hline Joint manifestations & $42(78)$ \\
\hline Convulsion & $2(4 \%)$ \\
\hline Pericarditis & $1(2)$ \\
\hline Anemia & $38(70)$ \\
\hline Leucopénia & $15(28)$ \\
\hline Thrombocytopenia & $5(9)$ \\
Low C3 & $43(80)$ \\
Low C4 & $41(76)$ \\
Anti-ds DNA & $49(91)$ \\
\hline &
\end{tabular}

\section{Histological features}

Renal biopsy was performed in all patients. It revealed mesangial glomerulonephritis (GN) (class II) in $15 \%$ of patients, focal proliferative GN (class III) in $28 \%$, diffuse proliferative GN (class IV) in $48 \%$ and extra membranous GN (class V) in $9 \%$. No class I or VI or combined classed were noted.

\section{Treatment and Outcomes}

All patients were treated with conservatively care. $33(61 \%)$ patients with joint and mucocutaneous manifestations received antimalarial drug.

All patients with proliferatives classes received a 3-day pulses of methylprednisolone followed by oral corticosteroids (CS) $(1 \mathrm{mg} / \mathrm{kg}$ body weight per day) and gradually tapered. After that, they received one of the 3 induction regimens: In one hand, 23 (43\%) patients received IV CYC of whom $8(15 \%)$ patients biweekly with low doses(500mg) during 3 months and 15 (28\%) patients monthly with high doses during 6 months $(15 \mathrm{mg} / \mathrm{kg})$, titrated to renal function, age and white blood cell. On the other hand, $18(33 \%)$ patients received oral MMF at a dose of 2-3g/day, splited.

Maintenance therapy was 2 years of $2 \mathrm{mg} / \mathrm{kg} /$ day AZA in $31(57 \%)$ patients or 1 to $2 \mathrm{~g} /$ day of MMF in $15(30 \%)$ patients as well as CS therapy.

At 6 months, Remission was achieved in 46 $(85 \%)$ patients. Complete remission was observed in 31
(57\%) patients and partial remission in 15 (28\%) patients. $8(15 \%)$ patients did not respond to treatment. Two of these patients required RRT and never left dialysis despite early initiation of immunosuppressive treatment.

We have recorded clinical and histological features of patients who did not respond to treatment. They represent $60 \%$ of male sex and all had at admission, proliferative classes with an advanced renal failure (eGFR less than $30 \mathrm{ml} / \mathrm{min}$ ) and higher arterial pressure. In addition, $87,5 \%$ of them had chronic lesions such as intersticial fibrosis, tubular atrophy and fibrous crescents.

Three deaths were due to extrarenal manifestations of the disease and side effects of immunosuppressive drugs. One patient developed lupus cerebretis and died because of severe status epilepticus. Two other deaths were due to sepsis.

Moreover, patients with proliferative classes were exposed to many adverse event comprising mostly infections $(41 \%)$, leukopenia $(20 \%)$, gastro intestinal symptoms $(31 \%)$ and menstruations abnormalities (24\%) (Table-3). Infections were distributed as follows: five viral infection including one reactivation of hepatitis $\mathrm{C}$ and 15 bacterial infections including pneumonia, urinary tract infection and bacterial meningitis in 6, 7 and 2 patients respectively. Two other patients had esophageal candidiasis. 
Steroid related adverse reactions included psychiatric disorders in 3 patients, cataract in 5, diabeties in 6 and cortisonic osteoporosis in 15 individuals.
Table-2 shows treatment and outcomes in our patients according to histological classes and Table-3 describes adverse events as stated by immunosuppressive therapy used.

Table-2: Treatment and outcomes of the 54 patients according to histological classes

\begin{tabular}{|l|l|l|l|l|l|l|l|}
\hline Classes of LN & I & II & III & IV & V & VI \\
\hline Number Treatment Induction & 54 & 0 & 8 & 15 & 26 & 5 & 0 \\
\hline MP+ OC & 49 & 0 & 5 & 15 & 26 & 3 & 0 \\
\hline CYC low dose & 8 & 0 & 0 & 3 & 5 & 0 & 0 \\
\hline CYC high dose & 15 & 0 & 0 & 4 & 11 & 0 & 0 \\
\hline MMF & 18 & 0 & 0 & 8 & 10 & 0 & 0 \\
\hline Maintenance AZA & 31 & 0 & 0 & 9 & 19 & 0 & 0 \\
\hline MMF & 15 & 0 & 0 & 7 & 6 & 0 & 0 \\
\hline HC & 33 & 0 & 7 & 10 & 16 & 0 & 0 \\
\hline Remission Overall & 46 & 0 & 8 & 12 & 21 & 5 & 0 \\
\hline Partial & 15 & 0 & 0 & 8 & 7 & 0 & 0 \\
\hline Complete & 31 & 0 & 8 & 4 & 14 & 5 & 0 \\
\hline No response & 8 & 0 & 0 & 3 & 5 & 0 & 0 \\
\hline ESRD & 2 & 0 & 0 & 0 & 2 & 0 & 0 \\
\hline Death & 3 & 0 & 0 & 1 & 2 & 0 & 0 \\
\hline
\end{tabular}

Table-3: Adverse events according to immunosuppressive therapy

\begin{tabular}{|l|l|l|}
\hline Adverse events & IV CYC n=24 & Oral MMF n=17 \\
\hline Infections & $15(62 \%)$ & $7(41 \%)$ \\
\hline Neutropenia & $3(12,5 \%)$ & $8(15 \%)$ \\
\hline Gastrointestinal symptoms & $5(29 \%)$ & $12(50 \%)$ \\
\hline Gonadol toxicity & $6(25 \%)$ & $7(41 \%)$ \\
\hline
\end{tabular}

\section{DISCUSSION}

The present study summarizes the11-year experience with renal biopsy proven $\mathrm{LN}$ at our center. It is among the few report in Morocco and North Africa showing the clinicopathological features and outcome of LN. The Moroccan populace has emerged from an incredible intermixing of communities, mostly made of Caucasians (Arabs and Berbers) and black Africans. The clinicopathological features of LN have been widely described from different geographical parts in the world [6-8, 12-17]. However, few reports exist on LN features in North African patients, particularly from Morocco. Thus, this study is an attempt to present LN features among a Moroccan population that is multiracial.
LN is one of the most common and frequent manifestations of SLE [1]. In a Moroccan report, Intissar et al indicated that renal disease revealed SLE in $75,4 \%$. Comparable results were found in our study. Nevertheless, in another work done by Chrysochou, LN uncovered SLE in just 36\%. This distinction may be due to contrast of racial attributes and indication of renal biopsy. Systemic manifestations in this work did not vary based on what was seen in different studies with transcendence of joint and skin involvements [6, 7, $18,19]$. As for renal manifestations, in our study, it was dominated by kidney injury, hematuria, proteinuria and hypertension .This is similar to that reported in many cohorts worldwide $[6,7,20]$, but with less renal failure may be due to the differente formulas used to estimate glomerular filtration rate in each series (Table-4).

Table-4: Renal manifestations of $\mathrm{LN}$ according to literature series

\begin{tabular}{|l|l|l|l|l|}
\hline & Our study & Intissar et al., [6] & Bono et al., [20] & Beji et al., [7] \\
\hline Number & 54 & 114 & 110 & 211 \\
\hline Renal failure & 48 & 59,6 & 77 & 51,6 \\
\hline Nephrotic syndrome & 28 & 52,6 & 45 & 47,4 \\
\hline Hypertension & 74 & 33,3 & 32,3 & 32,3 \\
\hline Hematuria & 74 & 76,3 & - & 75,3 \\
\hline
\end{tabular}

Renal biopsy performed in all our patients showed a predominance of diffuse proliferative classes which is in conformity with the available data published so far $[6,7,12,14,16,17]$. In contrast to these widely held findings, class III apparead more common in the series from Kuwait and Egypt [8, 13]. 
Moreover, no class I and class VI were seen in our study, similarly to a Saudi and Kuwaiti works [12, 13]. We speculate that the small size of these cohorts was not large enough to find these classes too. The frequency of various classes according to many ethnical groups worldwide is shown in Table-5.

Table-5: Comparison of histopathological classes in various ethnical groups

\begin{tabular}{|l|l|l|l|l|l|l|l|}
\hline \multirow{2}{*}{ Population } & \multirow{2}{*}{ No of biopsies } & \multicolumn{6}{|c|}{ Histological classes } \\
\cline { 3 - 9 } & & I & II & III & IV & V & VI \\
\hline $\begin{array}{l}\text { North Africans } \\
\text { Our study }\end{array}$ & 54 & 0 & 15 & 28 & 48 & 9 & 0 \\
\hline Morocco[6] & 96 & 3,1 & 2 & 10,4 & 62,5 & 8,3 & 3,1 \\
\hline Tunisia [7] & 211 & 4,7 & 4,7 & 28,2 & 45,9 & 15,2 & 1,2 \\
\hline $\begin{array}{l}\text { Arabs } \begin{array}{l}\text { SA [12] } \\
\text { SA }\end{array} \\
\text { Egypt [8] }\end{array}$ & 0 & 0 & 0 & 45 & 28 & 0 \\
\hline Kuwait [13] & 148 & 7,4 & 10,8 & 37,8 & 20,9 & 19,6 & 3,4 \\
\hline $\begin{array}{l}\text { Black Americans } \\
\text { Jamaica [14] }\end{array}$ & 66 & 0 & 6 & 54 & 40 & 0 & 0 \\
\hline $\begin{array}{l}\text { Black African } \\
\text { Senegal [15] }\end{array}$ & 22 & 0 & 23 & 6 & 48 & 9 & 5 \\
\hline $\begin{array}{l}\text { White european } \\
\text { Hungary [16] }\end{array}$ & 93 & 0 & 4,5 & 9 & 14,4 & 54,5 & 0 \\
\hline $\begin{array}{l}\text { Asian } \\
\text { China [17] }\end{array}$ & 183 & 2,1 & 9,6 & 19,3 & 46,2 & 18,2 & 4,3 \\
\hline
\end{tabular}

Corticosteroids combined with either CYC or $\mathrm{MMF}$ is the current standard of care induction regimen for severe LN regardless of race or ethnicity [21-23]. Nontheless, the preference of CYC or MMF is impacted by health economics and access to prompt diagnosis and treatment. In our study, all patients with proliferatives classes had received induction with either IV CYC (43\%) or oral MMF (33\%). At 6 months, remission occurred in $85 \%, 4 \%$ of patients progressed to ESRD and $6 \%$ died. Similar results were reported in an Italian study by Moroni et al: Of the $93 \mathrm{LN}$ patients followed up for 15 years, remission was obtained in 82 , $7 \%$ progressed to ESRD and death was noted in $6 \%$ [24]. This finding affirms results revealed by the European Journal of Human Genetics, indicating that Moroccans from North Western Africa are genetically closer to south Europeans than to Sub Saharan Africans [25]. However, in another Moroccan study [6], poor prognosis was reported with low remissions $(51 \%)$ and high relapses $(82 \%)$, which may be attributed to the low economic background of the patients $(57 \%)$ and the poor level of education conversely with our patients, most of whom had medical coverage. This shows that despite presenting with severe renal involvement, access to medical care is a key determinant of disease outcome and may likewise clarify incongruities in results even in same nation.

The data about histological examination which provides important information about renal outcome is still matter of debate [26]. Contreras et al showed that patients reaching the composite outcome of ESRD and death had predominantly proliferative LN with higher activity and chronicity index scores. Moreover, they had higher baseline mean arterial pressure and serum creatinine or proteinuria [27]. Same patient profile was found in our patients who did not respond to treatment. Taken together, these data uphold that histologic lesions especially proliferative and or chronic, foresee poor prognosis.

The main causes of death in our patients, as in patients from different parts of the world, have considerably changed from early complications, for example uncontrolled lupus disease to late difficulties such as infections caused by surplus of immunosuppressive therapies [28]. Thus, future challenges remain inducing remission with better tolerability and less toxicity.

From our view, the outcome of Moroccan patients with LN may be better than commonly thought. However, disparities seen from several studies in our country, can be assigned to the precariousness of health system and the low socioeconomic level of population.

\section{CONCLUSION}

Regardless of impressive advances in clinical management of LN and many enhancements undergone over the years, there are still information holes and unfulfilled clinical needs. Treatment responses and outcomes in Moroccan patients with LN compare favourably with patients from other parts of the world. The prevention and treatment of infective complications remain significant challenges in managing $\mathrm{LN}$ in Morocco.

\section{REFERENCES}

1. Brenner, B. M., Appel, G. B., Radhakrishnan, J., \& D'Agati, V. (2007). Secondary glomerular 
disease. In: The Kidney, edited by Brenner BM, 8th Ed., Philadelphia, PA, Saunders, pp 10671146.

2. Cameron, J. S. (1999). Lupus nephritis. Journal of the American Society of Nephrology, 10(2), 413424.

3. Adler, S., Cohen, A. H., \& Glassock, R. J. (1996). Secondary glomerular diseases. In: Benner BM (ed) The Kidney. Saunders: Philadelphia; 1498.

4. Grande, J. P. (1998). Mechanisms of progression of renal damage in lupus nephritis: pathogenesis of renal scarring. Lupus, 7(9), 604-610.

5. Austin III, H. A., Boumpas, D. T., Vaughan, E. M., \& Balow, J. E. (1994). Predicting renal outcomes in severe lupus nephritis: contributions of clinical and histologic data. Kidney international, 45(2), 544-550.

6. Haddiya, I., Hamzaoui, H., Tachfouti, N., Al Hamany, Z., Radoui, A., Zbiti, N., ... \& Bayahia, R. (2013). Features and outcomes of lupus nephritis in Morocco: analysis of 114 patients. International journal of nephrology and renovascular disease, 6, 249-258.

7. Beji, S., Kaaroud, H., Abderrahim, E., Goucha, R., Hedri, H., El Younsi, F., ... \& Maiz, B. (2005). Lupus nephritis: 211 cases. La Revue de medecine interne, 26(1), 8-12.

8. Barsoum, R. S., \& Francis, M. R. (2000). Spectrum of glomerulonephritis in Egypt. Saudi journal of kidney diseases and transplantation, 11(3), 421-429.

9. Weening, J. J., D’Agati, V. D., Schwartz, M. M., Seshan, S. V., Alpers, C. E., Appel, G. B., ... \& Nagata, M. (2004). The classification of glomerulonephritis in systemic lupus erythematosus revisited. Journal of the American Society of Nephrology, 15(2), 241-250.

10. Tan, E. M., Cohen, A. S., Fries, J. F., Masi, A. T., Mcshane, D. J., Rothfield, N. F., ... \& Winchester, R. J. (1982). The 1982 revised criteria for the classification of systemic lupus erythematosus. Arthritis \& Rheumatism: Official Journal of the American College of Rheumatology, 25(11), 1271-1277.

11. Cattran, D. C., Feehally, J., Cook, H. T., Liu, Z. H., Fervenza, F. C., Mezzano, S. A., ... \& Wetzels, J. F. (2012). Kidney disease: improving global outcomes (KDIGO) glomerulonephritis work group. KDIGO clinical practice guideline for glomerulonephritis. Kidney Supplements, 2(2), 139-274.

12. Alballa, S. R. (1995). Systemic lupus erythematosus in Saudi patients. Clinical rheumatology, 14(3), 342-346.

13. Al-Jarallah, K., Al-Awadi, A., Siddiqui, H., AlSalim, I., Shehab, D., Umamaheswaran, I., ... \& Malaviya, A. N. (1998). Systemic lupus erythematosus in Kuwait-hospital based study. Lupus, 7(7), 434-438.
14. Williams, W., Smith, R., Edwards, H., Sargeant, L. A., Smikle, M., \& Shah, D. (2007). The outcome of lupus nephritis in Jamaican patients. The American journal of the medical sciences, 334(6), 426-430.

15. Niang, A., Ka, E. F., Dia, D., Pouye, A., Kane, A., Dieng, M. T., .. \& Moreira-Diop, T. (2008). Lupus nephritis in Senegal: a study of 42 cases. Saudi Journal of Kidney Diseases and Transplantation, 19(3), 470-474.

16. Brugos, B., Kiss, E., Szodoray, P., Szegedi, G., \& Zeher, M. (2006). Retrospective analysis of patients with lupus nephritis: data from a large clinical immunological center in Hungary. Scandinavian journal of immunology, 64(4), 433-437.

17. Feng, P. H., \& Boey, M. L. (1996).Systematic lupus erythematosus in Chinese: the Singapore experience. Clin Rheumatol. 15:143-147.

18. Chrysochou, C., Randhawa, H., Reeve, R., Waldek, S., Wood, G. N., O’Donoghue, D. J., \& Kalra, P. A. (2008). Determinants of renal functional outcome in lupus nephritis: a single centre retrospective study. QJM: An International Journal of Medicine, 101(4), 313-316.

19. Rabbani, M. A., Tahir, M. H., Siddiqui, B. K., Ahmad, B., Shamim, A., Shah, S. M., \& Ahmad, A. (2005). Renal involvement in systemic lupus erythematosus in Pakistan. Journal of Pakistan Medical Association, 55(8), 328-332.

20. Bono, L., Cameron, J. S., \& Hicks, J. A. (1999). The very long-term prognosis and complications of lupus nephritis and its treatment. Qjm,92(4), 211-218.

21. HA III, A. U. S. T. I. N. (1986). Therapy of lupus nephritis. Controlled trial of prednisone and cytotoxic drugs. N Engl J Med, 314, 614-619.

22. Houssiau, F. A., Vasconcelos, C., D'Cruz, D., Sebastiani, G. D., Garrido, E. D. R., Danieli, M. G., ... \& Cervera, R. (2002). Immunosuppressive therapy in lupus nephritis: the Euro- Lupus Nephritis Trial, a randomized trial of low- dose versus high- dose intravenous cyclophosphamide. Arthritis Rheumatism, 46(8), 2121-2131.

23. Appel, G. B., Contreras, G., Dooley, M. A., Ginzler, E. M., Isenberg, D., Jayne, D., ... \& Wofsy, D. (2009). Mycophenolate mofetil versus cyclophosphamide for induction treatment of lupus nephritis. Journal of the American Society of Nephrology, 20(5), 1103-1112.

24. Moroni, G., Quaglini, S., Gallelli, B., Banfi, G., Messa, P., \& Ponticelli, C. (2007). The long-term outcome of 93 patients with proliferative lupus nephritis. Nephrology

Dialysis Transplantation, 22(9), 2531-2539.

25. Bosch, E., Calafell, F., Pérez-Lezaun, A., Clarimon, J., Comas, D., Mateu, E., ... \& Bertranpetit, J. (2000). Genetic structure of north- 
west Africa revealed by STR analysis. European Journal of Human Genetics, 8(5), 360-366.

26. Giannico, G., \& Fogo, A. B. (2013). Lupus nephritis: is the kidney biopsy currently necessary in the management of lupus nephritis?. Clinical Journal of the American Society of Nephrology, 8(1), 138-145.

27. Contreras, G., Pardo, V., Cely, C., Borja, E., Hurtado, A., De La Cuesta, C., ... \& Estrada, H. G.
(2005). Factors associated with poor outcomes in patients with lupus nephritis. Lupus, 14(11), 890895.

28. Yap, D. Y., Tang, C. S., Ma, M. K., Lam, M. F., \& Chan, T. M. (2012). Survival analysis and causes of mortality in patients with lupus nephritis. Nephrology Dialysis Transplantation, 27(8), 3248-3254. 